\title{
LOGÍSTICA REVERSA APLICADA EM UM SUPERMERCADO DE PEQUENO PORTE
}

\section{REVERSE LOGISTICS APPLIED IN A SUPERMARKET SMALL}

\author{
Data do recebimento do artigo: 22/04/2012 \\ Data do aceite do artigo: 03/09/2012 \\ Data da publicação: 29/11/2012
}

\author{
André Marcon Servilha ${ }^{1}$ \\ Graduação em Ciências Contábeis \\ Pontifícia Universidade Católica de São Paulo \\ Fernando de Almeida Santos \\ Doutorado em Ciências Sociais \\ Pontifícia Universidade Católica de São Paulo \\ Faculdade ENIAC
}

\section{RESUMO}

Este trabalho tem como objetivo dissertar sobre logística reversa e a sua importância no mundo globalizado. Posteriormente, é dissertado sobre a relação da logística reversa com o meio ambiente e com a logística verde. Ao final, apresenta-se um estudo de caso, que descreve o processo de logística reversa em um supermercado de pequeno porte situado em um bairro periférico da cidade de São Paulo, abordando os benefícios e resultados obtidos pela empresa abordada. Trata-se de uma pesquisa descritiva, que utiliza como forma de obtenção de informações a pesquisa em campo, pesquisas documentais e entrevistas com gestores e funcionários. Verificou-se que o papelão é o material que mais gera retorno ao supermercado com sua revenda, atingindo o valor de $\mathrm{R} \$ 2.679,92$ no ano. A venda das caixas de madeira, por sua vez, alcançou o valor anual de $\mathrm{R} \$ 1.791,00$ e a venda de plástico, alcançou o valor de $\mathrm{R} \$$ $1.534,08$ por ano. Esses números representam até quase $4 \%$ do faturamento líquido do supermercado. A pesquisa demonstrou que é possível desenvolver ações sustentáveis e de responsabilidade social, e ainda adicionar resultado econômico ao supermercado, ou seja, obter maior receita, mas, para isso, é necessário que a empresa reflita sobre suas ações.

Palavras-chave: Benefícios. Logística. Logística Reversa. Logística Verde. Resultados.

\begin{abstract}
This paper aims to elaborate on reverse logistics and its importance in a globalized world. Subsequently, is lectured on the relation of reverse logistics for the environment and green logistics. Finally, there is provided a case study that describes the process of reverse logistics into a small supermarket located in a suburb neighborhood of Sao Paulo, addressing the benefits and results achieved by the company addressed. This is a descriptive research, which uses as a way of getting information to field research, desk research and interviews with managers and employees. Has been found that the cardboard is the material which generates more return to the supermarket with its resale, reaching $\mathrm{R} \$ 2,679.92$ a year. The sale of wooden boxes, on the other hand, reached the annual amount of $\mathrm{R} \$ 1,791.00$ and the sale of plastic, reached the amount of $\mathrm{R} \$ 1,534.08$ per year. These numbers are up almost $4 \%$ of sales

\footnotetext{
1 Autor para correspondência: Pontifícia Universidade Católica de São Paulo - R. Monte Alegre, 984 - Perdizes, São Paulo - SP,Brasil - 05014-901
} 
for the supermarket. Research has shown that it is possible to develop sustainable and socially responsible actions, and even add economic results to the supermarket, or get more revenue, but for this it is necessary that the company ponders on their actions.

Keywords: Benefits. Logistics. Reverse Logistics. Green logistics. Results. 


\section{INTRODUÇÃO}

O trabalho disserta sobre a logística reversa e como seu uso pode ser relevante para a empresa que a aplica, bem como os ganhos da empresa em relação à competitividade, inovação e, principalmente, na imagem da marca na sociedade.

Enquanto a Logística trata do processo de fabricação, montagem, acabamento e saída do produto da indústria para o mercado, a Logística Reversa é justamente o processo inverso, é a área da logística da empresa responsável pelo retorno de bens de pós venda e pós-consumo, além de embalagens usadas ou produtos defeituosos.

Portanto, o objetivo da pesquisa consiste em estudar os processos de um supermercado (cujo nome, a pedido dos donos, não foi divulgado), a fim de identificar formas de melhorar a logística, reduzir custos, e contribuir com aspectos relacionados à sustentabilidade.

O trabalho possui como objetivos específicos identificar:

a. Se o empresário obtém lucro com o processo e o impacto destes valores mensalmente.

b. Os propósitos de um supermercado de periferia de ter atitudes consideradas sustentáveis.

c. As ações de um supermercado para a logística reversa e descrevê-las, pois o varejo hoje é uma das principais fontes de material reciclável, impactando no meio-ambiente.

O trabalho analisa a seguinte problematização: É possível um supermercado de pequeno porte desenvolver ações de responsabilidade social e, ainda, aumentar a sua sustentabilidade econômica, ou seja, trazer resultados para o negócio?

De acordo com Braga Junior (2007, p.17): "Empresas comprometidas socialmente e ambientalmente são reconhecidas pelo consumidor final". É esse conceito que foi trabalhado no decorrer da pesquisa, pois considera, que com o mundo globalizado, as grandes empresas são obrigadas a criarem diferenciais frente às suas concorrentes, para assim se manterem fortes nos concorridos mercados atuais.

O trabalho foi desenvolvido em três partes. As duas primeiras foram elaboradas por meio de pesquisa bibliográfica e, na terceira, é apresentado um estudo de caso, conforme descritos a seguir:

A primeira parte aborda brevemente os conceitos básicos de logística, além de destacar os custos envolvidos no processo logístico.

Na segunda parte, é abordada a logística reversa, assim como seus canais-reversos de pós-venda e pós-consumo.

$\mathrm{Na}$ última parte, é descrito o estudo de caso, que apresenta os números relativos ao desempenho de um mercado que aplica a logística reversa, sendo que as informações foram obtidas por meio de visitas in loco, entrevistas com o gerente e outros funcionários e análise de documentos do supermercado. A entrevista foi realizada de forma roteirizada e com caráter qualitativo.

O objetivo da pesquisa in loco foi analisar os procedimentos do supermercado, entrada e saída de produtos, resíduos e também eventuais sobras de materiais. Com auxílio dos donos do supermercado foi possível fazer análises sobre a logística reversa do estabelecimento. 
O supermercado foi visitado sete vezes durante o decorrer do trabalho, foram entrevistados, de maneira informal, cerca de cinco funcionários que trabalham no supermercado, e também o dono do supermercado, porém esse foi entrevistado formalmente.

As entrevistas feitas no local abordaram sobre a opinião e conhecimento dos funcionários e do dono sobre como a logística reversa é utilizada pelo supermercado e o impacto nos resultados.

\section{LOGÍSTICA.}

\subsection{CONCEITO DE LOGÍSTICA}

Segundo Rogers and Tibben-Lembke (1999, p. 2), logística é definida pelo Conselho de Gestão de Logística como:

$O$ processo de planejamento, implementação e controle do fluxo e armazenagem eficientes e de baixo custo de matérias primas, estoque em processo, produto acabado e informações relacionadas, desde o ponto de origem até o ponto de consumo, com o objetivo de atender aos requisitos do cliente.

As empresas com o decorrer do tempo precisavam de um gerenciamento lógico, para dar conta da demanda de produtos, ter o controle de sua produção, venda, demanda, bem como facilitar o acesso para que seus produtos chegassem a lugares distantes, já que antes o custo do frete do produto para uma localidade maior chegava até a superar o custo do próprio produto.

Segundo Christopher (1997, p.3) apud. Lago, Lotici e Silva (2008, p.2):

Logística é o processo de gerenciar estrategicamente a aquisição, movimentação e armazenagem de materiais, peças e produtos acabados (e os fluxos de informações correlatas) através da organização e seus canais de marketing, de modo a poder maximizar as lucratividades presente e futura através do atendimento dos pedidos a baixo custo.

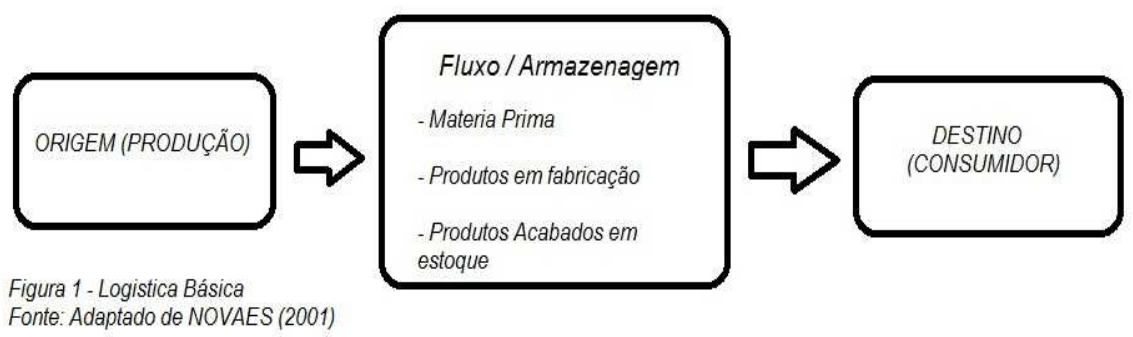

Analisando a figura adaptada de Novaes (2001, p. 36), observa-se um conceito básico de logística, onde a primeira parte é a fabricação do produto, classificado como ORIGEM, porém nesse primeiro ponto também podem ser incluídos os fornecedores, por exemplo. Na segunda, é demonstrada a armazenagem dos produtos que estão sendo feitos, bem como os acabados que estão em estoque, como matérias primas, produtos em fabricação ou acabados, entre outros. A terceira parte da figura representa o consumidor final, ou mercado/loja onde os produtos serão 
vendidos aos consumidores, classificados como DESTINO. Demonstra de forma sucinta o "caminho que a logística tem que percorrer" o mais rápido possível, e com o menor custo durante todo o processo.

\subsection{CUSTOS LOGÍSTICOS}

Os custos logísticos são todos os custos que uma empresa gasta com sua logística, entre os quais se destacam os custos de armazenagem e os custos de transporte. Os custos logísticos só não são mais importantes do que o custo do próprio produto, e um bom controle estratégico é fundamental para a redução desses custos, gerando assim mais lucros para a empresa.

De acordo com Rogers e Tibben-Lembke (1998, p. 17-18) apud Chaves e Chicarelli (2005, p. 37):

\footnotetext{
Em pesquisa realizada com grandes companhias nos Estados Unidos por Rogers e Tibben-Lembke (1998), mais de $20 \%$ das empresas informaram que recapturar valor $e$ recuperar ativos era estratégico e outros $20 \%$ fazem uso da logística reversa para proteger suas margens de lucro. As empresas que começaram programas de recuperação de bens recentemente perceberam que uma porção surpreendentemente grande dos seus lucros se origina de programas de recuperação de bens. Estes programas somam lucro derivado de materiais que eram previamente descartados.
}

Sobre a margem de custos de uma empresa, segundo LACERDA (2002, p. 476) as empresas vêm conseguindo economizar com a redução de seus custos no processo logístico, um exemplo é a reciclagem de latas de alumínio, onde segundo LEITE (2003, p.121), "há uma economia de $95 \%$ de energia elétrica utilizada na fabricação do alumínio primário". Este custo fica em expressão considerando que a energia elétrica representa $70 \%$ dos custos totais da fabricação do alumínio.

\section{LOGÍSTICA REVERSA}

\subsection{CONCEITO DE LOGÍSTICA REVERSA.}

No mercado globalizado os detalhes podem ser relevantes, e as empresas buscam cada vez mais formas de economizar sem prejudicar seu ciclo produtivo, além de não sofrerem eventuais gargalos ou desperdícios. Logo, a logística reversa é uma ferramenta para que as empresas reaproveitem produtos ou materiais, que antes não tinham mais utilidade por já serem considerados como lixo ou sucata.

Segundo CHAVES e CHICARELLI (2005, p. 2), a evolução do conceito de logística reversa está relacionada com o aumento da preocupação em relação às questões ambientais, e também com a preocupação em relação aos custos das organizações.

Leite (2003, p. 16-17) define a logística reversa como:

A área da logística empresarial que planeja, opera e controla o fluxo e as informações logísticas correspondentes, do retorno dos bens de pós-venda e de pós-consumo ao ciclo de negócios ou ao ciclo produtivo, por meio dos canais de distribuição reversos, agregando-lhes valor de diversas naturezas: econômico, ecológico, legal, logístico, de imagem corporativa, entre outros. 
Para Rogers e Tibben-Lembke (1999 apud ROSA, 2008, p.3), logística reversa é definida como:

[...] O processo de planejamento, implementação e controle do fluxo de matérias primas, estoque em processamento e produtos acabados (e seu fluxo de informação) do ponto de consumo até o ponto de origem, com objetivo de recuperar valor ou realizar um descarte adequado.

Fontana e Aguiar (2001, p.212) apud Rosa (2008, p.4) afirmam que:

A logística reversa representa todos os assuntos relacionados com as atividades logísticas cumpridas como o objetivo de redução, reciclagem, substituição, reúso de materiais e a disposição final. Os aspectos ambientais têm um profundo impacto no trabalho logístico.

A logística reversa atua no caminho contrário da logística; enquanto a logística tem como função levar o produto ao consumidor, a logística reversa tem como função fazer com que o produto usado, gasto, descartado ou consumido retorne para a empresa, que irá ou dar os fins corretos ao produto ou reutilizar o mesmo em seu processo de produção, reduzindo assim os custos com matéria prima, por exemplo.

Para o reaproveitamento, os produtos devem passar por várias etapas, até que o processo seja concluído. As etapas são: coleta, separação de resíduos ou produtos, embalagem, entre outros.

A logística reversa tem papel fundamental na agregação de valor ao produto, que por diversos motivos já citados são obrigados a voltar para a fábrica antes de poder voltar ao mercado novamente.

\subsection{PROCESSO LOGÍSTICO REVERSO}

Na figura apresentada, a seguir, pode-se observar um ciclo logístico, onde é apresentado o processo logístico e o processo logístico reverso. Os bens e serviços vão para os consumidores por meio deste processo logístico e depois retornam ao início do ciclo novamente pela logística reversa, para reparo, ou reaproveitamento dos mesmos. Nesse ponto, se agrega novos valores aos produtos já usados. 


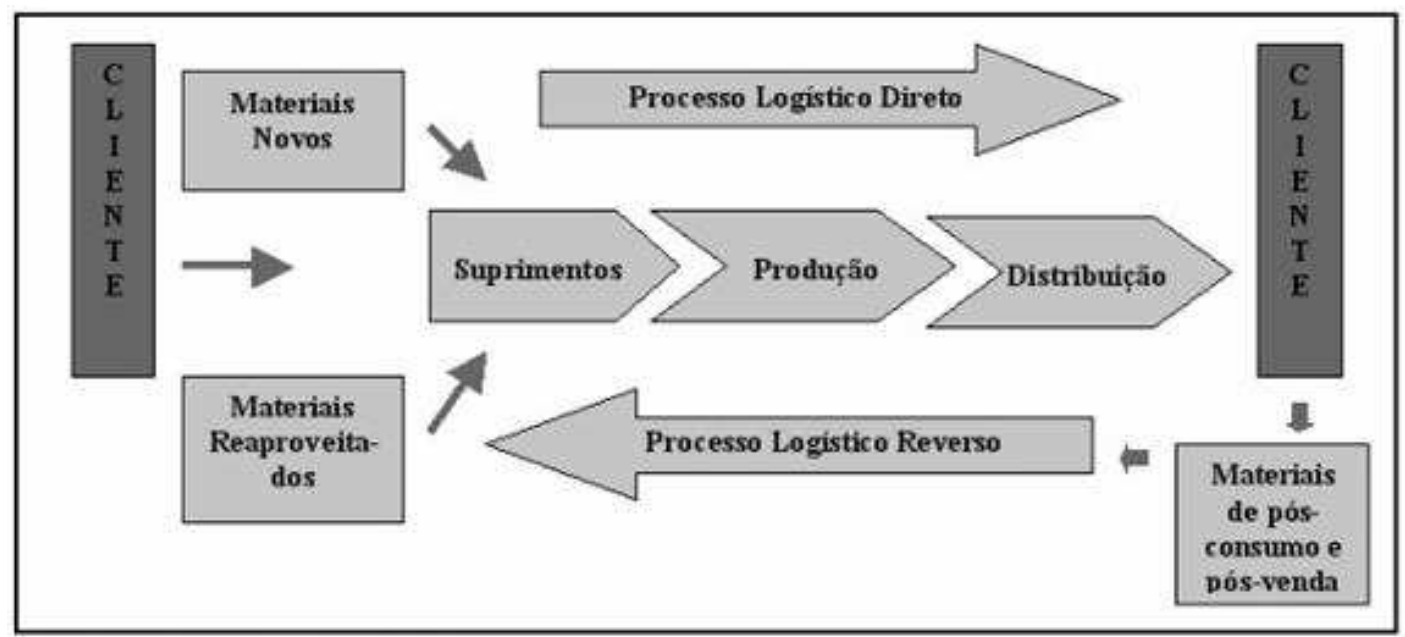

Figura 2 - Processo Logístico Reverso

Fonte: Adaptado de Lacerda $(2002$, p.2)

O processo logístico pode ser usado, tanto para bens pós-venda, quanto para bens pósconsumo, conforme o caso. Em ambos os momentos, há possibilidade de desenvolver a logística reversa para que o produto volte ao ponto de origem para reparo ou reposição.

\subsection{CANAIS DE DISTRIBUIÇÃO REVERSA DE PÓS-CONSUMO}

Segundo Leite (2006) apud Acosta Wegner e Padula (2008, p. 3), "é importante explicar o que são canais de distribuição reversos, como a base de tudo o que constitui um sistema de logística reversa".

Para Torre (2009, p. 28), "a logística reversa de pós-consumo é responsável pelo retorno de bens e suas partes integrantes, que recebem tratamento diferenciado, dependendo do estado e origem".

Sobre a implementação da logística reversa de pós-consumo, Leite (2006) apud. Acosta Wegner e Padula, (2008, p. 4) afirma que:

O objetivo econômico da implementação da logística reversa de pós-consumo é a obtenção de resultados financeiros por meio de economias obtidas nas operações industriais, principalmente pelo aproveitamento de matérias-primas secundárias, provenientes dos canais reversos de reciclagem, ou de revalorizações nos canais reversos de reúso e de remanufatura.

Sobre os canais de distribuição reversa de pós-consumo, Acosta Wegner e Padula (2008, p. 3) afirmam que:

Estão constituídos pelo fluxo reverso de produtos e de materiais originados no descarte de produtos, depois de finalizada sua utilidade principal (fim de vida útil) e que retornam ao ciclo produtivo de alguma forma (revalorização). Uma vez que o produto atinge seu fim de vida útil, este pode ser revalorizado por meio do canal reverso de desmanche ou de reciclagem. Se por nenhum destes meios o bem de pós-consumo conseguiu ser revalorizado, encontra a disposição final em aterros sanitários ou é incinerado. 
Zimermann e Graeml (2003) apud. Pires (2007, p. 42) destacam os motivos que uma empresa tem para priorizar a utilização dos bens de pós-consumo:

a) Reaproveitamento de componentes ou materiais: Reutilização de produtos ou de seus componentes e materiais.

b) Incentivo à nova aquisição: Benefício proposto na troca de um item usado por um novo.

c) Revalorização ecológica: Promover a imagem da empresa, vinculando a imagem à responsabilidade ética da empresa.

Sobre as iniciativas relacionadas à logística reversa, Guarnieri et al. (2005) apud. Pires (2007, p.44) cita que:

As iniciativas que vêm sendo tomadas em relação à logística reversa de pós-consumo trazem às empresas uma compensação em seus custos, minimizam penalidades legais e aumentam sua lucratividade, além de potencializarem um novo nicho de mercado.

De acordo com Leite (2006) apud Acosta Wegner e Padula (2008, p.3), os canais de distribuição reversa de pós-consumo são:

\section{a) Canal reverso de reúso}

Bens que retornam ao mercado para o "reúso", pois já foram usados ou consumidos e não estão mais em condições de uso. No canal reverso de reúso, ocorre o prolongamento da vida útil do produto, que volta ao mercado como item de "segunda mão".

De acordo com Torre (2009, p. 28) o canal reverso de reúso permite o "prolongamento da vida útil do bem, [...] esses produtos farão parte dos produtos de segunda mão, até seu esgotamento total".

\section{b) Canal reverso de desmanche}

No desmanche os produtos já estão no fim de sua vida útil, ou seja, não podem ser mais usados nem no mercado secundário, portanto, restam duas alternativas: a reciclagem ou o desmanche.

\section{c) Canal reverso de reciclagem}

$\mathrm{Na}$ reciclagem, a própria empresa (ou qualquer outra empresa) recicla o produto, de forma a poder reutilizá-lo como matéria prima para a fabricação de outro produto, economizando, assim, matéria prima.

Segundo Rosa (2008, p. 10-11), as etapas da reciclagem são: Coleta, Separação, Revalorização e Transformação.

\section{d) Canal reverso de disposição final}

No canal reverso de disposição final, o produto será descartado, pois já não é possível mais nenhuma agregação de valor ao mesmo, porém isso deverá ser feito de maneira correta, de 
modo que não afete o meio ambiente, e em locais controlados, como aterros sanitários, de modo a ocorrer absorção natural, ou então também podem ser incinerados.

\section{e) Canal de distribuição reversa de pós-venda}

A logística reversa de bens de pós-venda tem como principal característica o retorno de produtos que, por algum motivo, apresentaram algum tipo de defeito, fazendo, assim, com que o cliente manifestasse seu desejo de devolução ou troca do mesmo, que ocorre por conta da empresa ou fábrica do bem, que foi vendido com problema.

Rosa (2008, p. 6) tem uma definição para a logística reversa de pós-venda onde fica evidenciado que empresas que utilizam os canais de distribuição reversos, como ferramenta em seu ciclo produtivo têm certa vantagem competitiva frente às que não fazem o mesmo:

Destaca-se na logística reversa de pós-venda o fator diferencial competitivo, pois dá suporte ao cliente evidenciando a atenção e fidelidade, garantindo-lhe a possibilidade de recusa ou troca de produtos.

\section{f) Canal reverso de retornos comerciais}

O canal reverso de retornos comerciais tem como principais causas devoluções, por conta de estoques excessivos no canal de distribuição, produtos enviados diferentemente do anúncio (em caso de compras pela internet) entre outros.

\section{g) Canal reverso de garantia / qualidade}

De acordo com Castro et al. (2008, p. 51), "as devoluções por garantia / qualidade são as que ocorrem por defeitos de fabricação, mau funcionamento, avarias do produto ou embalagens e problemas relacionados com a qualidade" e, por isso, devem voltar para a empresa fabricante para seu reparo ou desmanche, identificando, assim, a peça com defeito e reutilizando as que não apresentarem defeito algum. Nesse processo ocorre a agregação de valor ao produto, que retorna ao mercado primário ou secundário depois de ser reparado. As devoluções por qualidade também ocorrem quando o produto está estragado ou violado.

\section{h) Canal reverso de devoluções por qualidade intrínseca}

As devoluções por qualidade intrínseca ocorrem por motivos previstos em leis de proteção ao consumidor, garantindo, assim, que o consumidor não seja lesado.

Segundo Castro et al. (2008, p. 51), também se enquadram neste item, produtos que chegam aos consumidores finais danificados, isso pode ocorrer durante o trajeto de entrega, ou seja, antes do produto, chegar de fato, ao consumidor, esses acidentes podem ocorrer no percurso, ou no manuseio dos produtos nos centros de distribuições que o produto transita quando o destino final é longe da fábrica. Quando a carga é valiosa as distribuidoras fazem seguros contra eventuais acidentes, furtos ou extravios durante a logística de entrega.

\subsection{FATORES CRÍTICOS QUE INFLUENCIAM A EFICIÊNCIA DO PROCESSO DE LOGÍSTICA REVERSA}


A figura a seguir demonstra os principais fatores críticos que contribuem positivamente para o desempenho do sistema de logística reversa.

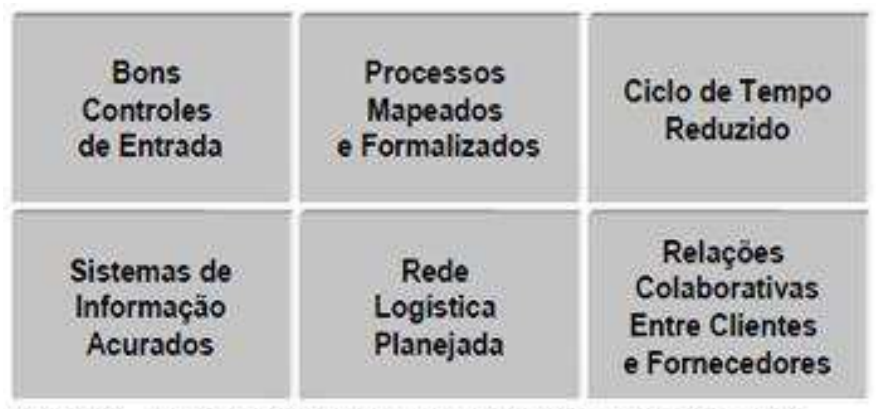

Figura 3 - Fatores críticos e que contribuem positivamente para o desempenho do sistema de logistica reversa. Fonte: Lacerda (2002, p.5)

São eles:

\section{a) Bons controles de entrada}

Para que os materiais que retornam pelo processo de logística reversa tomem o fluxo reverso correto é preciso identificar corretamente o estado em que esses materiais se encontram, pois alguns ainda podem ser revendidos, e, portanto, não entrariam no fluxo e outros já chegaram totalmente ao fim de sua vida útil, não sendo possível, assim, agregar qualquer tipo de valor ao produto. Se o sistema de logística reversa não tem um controle de entrada preciso, isso pode causar consequências em todo o processo logístico, podendo ocorrer perca de tempo e de esforço nas fases seguintes do processo.

\section{b) Processos padronizados e mapeados}

Segundo Lacerda (2002, p. 6), "uma das maiores dificuldades na logística reversa é que ela é tratada como um processo esporádico, contingencial e não como um processo regular", portanto os processos devem ser corretamente padronizados e mapeados para se obter ganhos de controle e outras melhorias.

\section{c) Ciclo de tempo reduzido}

Segundo Lacerda (2002, p. 6), o ciclo de tempo ocorre "entre a identificação da necessidade de reciclagem, disposição ou retorno de produtos e seu efetivo processamento", portanto, quanto menor for esse tempo, melhor, pois tempos longos atrasam o ciclo e geram despesas adicionais, como acumulo de estoque (sucata), ocupando, assim, espaço, e também certo atraso nos recebimentos de caixa, pois a sucata ainda não foi vendida.

\section{d) Sistemas de informação acurados}

Quanto melhor for o sistema de informação mais eficiente e eficaz será o processo de logística reversa. Segundo Torre (2009, p. 27), "São sistemas capazes de lidar com o nível de variações e flexibilidade exigida pelo processo de logística reversa". 


\section{e) Rede logística planejada}

É preciso toda uma rede logística interligada, para que o sistema logístico reverso funcione. Assim como no sistema logístico normal, é preciso haver componentes da cadeia logística para que haja armazenagem, facilidade no transporte, economia com eventuais perdas, entre outros.

\section{f) Relações colaborativas entre clientes e fornecedores}

As relações colaborativas entre clientes e fornecedores consistem em um aspecto de muita discussão no planejamento logístico reverso, pois deve haver certa confiança entre varejista e fornecedor, pois quando algum produto apresenta certo tipo de defeito o varejista pode, por exemplo, "culpar" o fornecedor, que por sua vez, pode acreditar que o produto apresentou defeito devido aos maus tratos do varejista.

\subsection{LOGÍSTICA VERDE E QUESTÕES AMBIENTAIS}

O processo logístico reverso pode trazer significativos ganhos para a empresa, tanto em relação aos custos quanto em relação à satisfação e fidelização de seus clientes. Portanto a empresa que almeja um destaque no mercado deve sempre estar atenta quanto à sua imagem, aspecto relevante para o sucesso da organização.

Segundo Robles Jr e Bonelli (2006, p. 51):

Do ponto de vista empresarial, quando se mencionam qualidade e meio ambiente sob o aspecto econômico, a ideia inicial é a de que haverá aumento das despesas e o consequente acréscimo dos custos do processo produtivo. Na realidade um sistema de gestão ambiental estruturado, com metas estabelecidas, consegue se autofinanciar, pois tecnologias limpas, mudanças de processos e tratamento de resíduos tornam possível contabilizar ganhos.

As empresas tendem cada vez mais a se preocupar com as questões ambientais, justamente porque uma empresa que agride o meio ambiente logicamente não será bem vista por parte de seus clientes. Outro grande fator que contribui para que as empresas sejam ecologicamente corretas é a pressão por parte da legislação, e, também, a pressão por parte de ONGs que sempre protestam e lutam a favor do meio ambiente.

Segundo Torre (2009, p.41):

O objetivo atual do desenvolvimento sustentável é melhorar a qualidade de vida do planeta, a fim de não comprometer as gerações futuras, para isso as empresas não precisam deixa de produzir, mas sim absorver matéria-prima do meio ambiente de forma consciente e após o uso de seus produtos praticam um sistema de logística Verde, agregando valor a produtos que seriam descartados no meio ambiente. 


\subsection{CONCEITO, DIFERENÇAS E RELAÇÃO ENTRE A LOGÍSTICA VERDE E A LOGÍSTICA REVERSA.}

Segundo Torre (2009, p. 31), a logística verde é facilmente confundida com logística reversa, isso porque as duas podem tratar do mesmo assunto, por exemplo, o recolhimento de produtos que afetam o meio ambiente, este é um exemplo de logística verde, pois o produto em questão de fato afeta o meio ambiente, mas também é um exemplo de logística reversa, pois esse mesmo produto será reaproveitado ou terá um descarte ecologicamente correto.

De acordo com Rogers e Tibben-Lembke (1999), apud. Torre (2009, p. 35), "logística verde é toda atividade da qual consistem nos esforços para medir e minimizar o impacto ecológico das atividades logísticas”.

Segundo Torre (2009, p. 35), "a logística verde considera todo o impacto, desde a produção do bem, até o fim de sua vida útil e a correta destinação final do bem”. Moura (2000) apud. Torre (2009, p. 35) destaca que:

Este conceito de logística verde concentra-se em impor um limite rigoroso à poluição
ambiental gerada no processo de logística e garantir um sistema de reciclagem de
baixa poluição e um fluxo logístico que não agrida o meio ambiente. A logística verde
permite que o papel essencial da produção seja o de transformar os recursos limitados
do meio ambiente em algo útil para o estilo de vida e a cultura das pessoas.

Portanto, existem diferenças entre logística verde e logística reversa, enquanto a logística reversa tem como principal função inserir novamente no mercado produtos anteriormente descartados nos ciclos de negócios, a logística verde estuda formas de diminuir os impactos causados pela logística comum ao meio ambiente e atender aos princípios de sustentabilidade ambiental. Um exemplo prático da diferença entre as duas é a tentativa de redução do consumo de energia durante um processo produtivo ou logístico, pois, neste exemplo, trata-se de pura logística verde, o consumo de energia não está atrelado à logística reversa.

\section{ESTUDO DE CASO SOBRE A LOGÍSTICA REVERSA EM UM SUPERMERCADO DE PEQUENO PORTE 4.1. ASPECTOS GERAIS DO SUPERMERCADO}

O estudo de caso deste trabalho foi feito com base em um supermercado de bairro, localizado na zona sul de São Paulo, Brasil, com sede própria, cujo nome não será divulgado por solicitação dos proprietários. Foram analisados os dados financeiros do supermercado em questão, bem como a rotina de trabalho de seus funcionários e colaboradores quanto à logística reversa aplicada pelo supermercado.

O supermercado foi fundado em 1991 e ocupa uma área de aproximadamente $600 \mathrm{~m}^{2}$, sendo frequentado quase que por completo pelos moradores da região, pois, como o supermercado está situado em uma região periférica, é inviável para os moradores que saiam do bairro para fazer compras, pois a maioria nem possui veículos, e mesmo os que possuem, não querem ter o trabalho de ir a um hipermercado.

Atualmente, o supermercado tem mais de 30 funcionários, que revezam os turnos e os finais de semanas que irão trabalhar. O supermercado não tem franquias nem outras lojas. 


\subsection{ANÁLISE DO SUPERMERCADO}

Nas visitas feitas ao local foi possível analisar o método utilizado pelo supermercado para estocagem das sobras, que em sua grande maioria são de papelão e também plásticos. Há uma área reservada para que funcionários depositem ali as sobras de papelão e outra área para que depositem plástico, que no fim são vendidos separadamente para uma empresa que busca esses resíduos de duas a três vezes por semana no próprio supermercado.

Segundo o dono do supermercado, desde 2003 as sobras de papelão e plástico são vendidas, porém antes o valor era fixo e a empresa que comprava e buscava as sobras de materiais era outra, em 2006 o supermercado trocou sua parceria, vendendo agora os materiais a uma nova empresa, que compra os resíduos até hoje.

Essa empresa que recolhe os materiais paga ao supermercado cerca de dez centavos por quilo de papelão e vinte e cinco centavos por quilo de plástico. Os valores foram revelados pelo próprio dono do supermercado, que garante que os preços estão dentro do padrão da região.

A estocagem das sobras de papelão e plásticos fica próximo ao portão de saída do galpão, na área do estoque, justamente para facilitar a retirada desses resíduos pelos funcionários da empresa que recolhem os resíduos. Aliás, os restos de plásticos e papelão já saem prensados, pois segundo o sócio, devido à dificuldade para os funcionários pesarem e carregarem os resíduos do local estocado até o caminhão, a empresa que recolhe o papelão e plástico forneceu uma prensa e uma balança para o supermercado, que agora já prensa todo o plástico e papelão para facilitar o transporte e pesagem do mesmo.

Antes, a pesagem era feita na própria empresa recolhedora, porém, desta forma o supermercado nunca tinha certeza se aquele peso era realmente verdadeiro ou não, agora o controle de peso dos materiais é feito internamente, e depois conferido pela empresa recolhedora, desta forma o supermercado pode ter um melhor controle do montante de plástico e papelão que está sendo vendido.

O supermercado fornece, também, as caixas de papelão para clientes que, eventualmente, aparecem por lá para pedir algumas caixas. Destaca-se que, elas são doadas para os clientes, ou seja, nada é cobrado em troca dessas caixas de papelão.

$\mathrm{O}$ faturamento mensal do supermercado varia de acordo com os meses em épocas de carnaval, natal e réveillon o faturamento líquido é maior, porém, nos demais meses, o faturamento líquido varia entre dez e quinze mil reais, segundo o dono do supermercado.

Atualmente, baseado nas notas fiscais que o sistema do mercado contabiliza, o fluxo médio de clientes atendidos por dia é de mil pessoas, em algumas épocas como em feriados, natal e réveillon, esse numero costuma ser maior. Em meses como Dezembro, o montante de papelão e plásticos vendidos chega a quase três toneladas e meia, sendo que nos demais meses o normal é que sejam vendidas aproximadamente 2,2 toneladas de papelão e 0,5 toneladas de plástico por mês.

As frutas e verduras chegam ao mercado em caixas de plástico, papelão e madeira, sendo que, as caixas de madeiras já têm destino certo, retornam aos fornecedores da CEAGESP Companhia de Entrepostos e Armazéns Gerais de São Paulo, para serem reutilizadas.

O hortifrúti do supermercado é composto por poucos tipos de frutas e legumes, há apenas frutas mais convencionais, como banana, pera, maçã, e outras. Por mês o supermercado usa 
uma média de 300 caixas de madeira para o transporte de suas frutas, legumes e verduras, as caixas de papelão são revendidas juntamente com o montante de papelão acumulado no estoque do supermercado.

As caixas de madeiras teoricamente seriam descartáveis, não podendo ser reutilizadas, porém, no caso do supermercado, elas acabam voltando para os "caixeiros" da CEAGESP, que são os responsáveis pela reconstrução das caixas de madeiras quebradas ou depredadas. Toda semana o caminhão parte para buscar frutas e legumes na CEAGESP, e junto leva algumas caixas de madeira vazias. As caixas são vendidas aos "caixeiros" pelo preço de cinquenta centavos cada caixa, que depois vão ser reutilizadas, porém sem a devida higienização.

\subsection{ANÁLISE DE RESULTADOS}

Após análise dos dados relativos à coleta e venda de produtos recicláveis, foi possível observar que:

\begin{tabular}{|c|r|r|r|r|}
\hline MÊS & $\begin{array}{c}\text { LUCRO } \\
\text { LÍQUIDO }-\mathrm{R} \$\end{array}$ & $\begin{array}{c}\text { VENDA DE } \\
\text { PAPELÃO - KG }\end{array}$ & $\begin{array}{c}\text { VENDA DE } \\
\text { PLÁSTICO - KG }\end{array}$ & $\begin{array}{c}\text { VENDA DE CAIXA } \\
\text { DE MADEIRA - } \\
\text { Unidades }\end{array}$ \\
\hline Julho/10 & $13.845,36$ & $2.286,86$ & 522,30 & 303 \\
\hline Ago./10 & $11.798,39$ & $2.060,39$ & 491,23 & 285 \\
\hline Set./10 & $12.483,90$ & $2.140,46$ & 501,25 & 258 \\
\hline Out/10 & $12.942,74$ & $2.210,75$ & 524,82 & 320 \\
\hline Nov./10 & $13.661,18$ & $2.358,19$ & 525,31 & 320 \\
\hline Dez/10 & $14.883,25$ & $2.412,64$ & 538,13 & 317 \\
\hline Jan./11 & $14.289,51$ & $2.369,15$ & 531,44 & 291 \\
\hline Fev./11 & $13.771,28$ & $2.187,62$ & 480,31 & 289 \\
\hline Mar/11 & $13.085,20$ & $2.201,40$ & 502,26 & 292 \\
\hline Abr./11 & $12.584,12$ & $2.040,80$ & 491,87 & 295 \\
\hline Mai./11 & $13.652,89$ & $2.238,59$ & 500,28 & 309 \\
\hline Jun./11 & $13.341,28$ & $2.292,35$ & 527,10 & $3.136,30 \mathrm{KG}$ \\
\hline TOTAL & $\mathrm{R} \$ 160.339,10$ & $26.799,20 \mathrm{KG}$ & & 3.582 UNIDADES \\
\hline
\end{tabular}

Tabela 1 - Análise dos dados em kg e em unidades.

Fonte:Dados da pesquisa. 
A tabela apresentada foi feita com base em $\mathrm{Kg}$ e em unidades, a tabela a seguir está toda convertida em reais:

\begin{tabular}{|c|c|c|c|c|}
\hline MÊS & $\begin{array}{c}\text { LUCRO } \\
\text { LÍQUIDO - R\$ }\end{array}$ & $\begin{array}{c}\text { VENDA DE } \\
\text { PAPELÃO - R\$ }\end{array}$ & $\begin{array}{c}\text { VENDA DE } \\
\text { PLÁSTICO - R\$ }\end{array}$ & $\begin{array}{c}\text { VENDA DE CAIXA DE } \\
\text { MADEIRA - R \$ }\end{array}$ \\
\hline Julho/10 & $13.845,36$ & 228,69 & 130,58 & 151,50 \\
\hline Ago./10 & $11.798,39$ & 206,04 & 122,81 & 142,50 \\
\hline Set./10 & $12.483,90$ & 214,05 & 125,31 & 129,00 \\
\hline Out/10 & $12.942,74$ & 221,08 & 131,21 & 160,00 \\
\hline Nov./10 & $13.661,18$ & 235,82 & 131,33 & 151,50 \\
\hline Dez/10 & $14.883,25$ & 241,26 & 134,53 & 160,00 \\
\hline Jan./11 & $14.289,51$ & 236,92 & 132,86 & 158,50 \\
\hline Fev./11 & $13.771,28$ & 218,76 & 120,08 & 145,50 \\
\hline Mar/11 & $13.085,20$ & 220,14 & 125,57 & 144,50 \\
\hline Abr./11 & $12.584,12$ & 204,08 & 122,97 & 146,00 \\
\hline Mai./11 & $13.652,89$ & 223,86 & 125,07 & 147,50 \\
\hline Jun./11 & $13.341,28$ & 229,24 & 131,78 & 154,50 \\
\hline TOTAL & $\mathrm{R} \$ 160.339,10$ & $\mathrm{R} \$ 2.679,94$ & $\mathrm{R} \$ 1.534,10$ & $\mathrm{R} \$ 1.791,00$ \\
\hline MÉDIA & $13.361,59$ & $\mathrm{R} \$ 223,33$ & $\mathrm{R} \$ 127,84$ & $\mathrm{R} \$ 149,25$ \\
\hline
\end{tabular}

Tabela 2 - Análise dos dados em reais.

Fonte: Dados da pesquisa.

Para melhor visualização, com os dados obtidos, é possível visualizar os resultados por meio de gráficos em relação à variação da receita obtida com reciclagem em função do lucro líquido do supermercado é possível obter o seguinte gráfico:

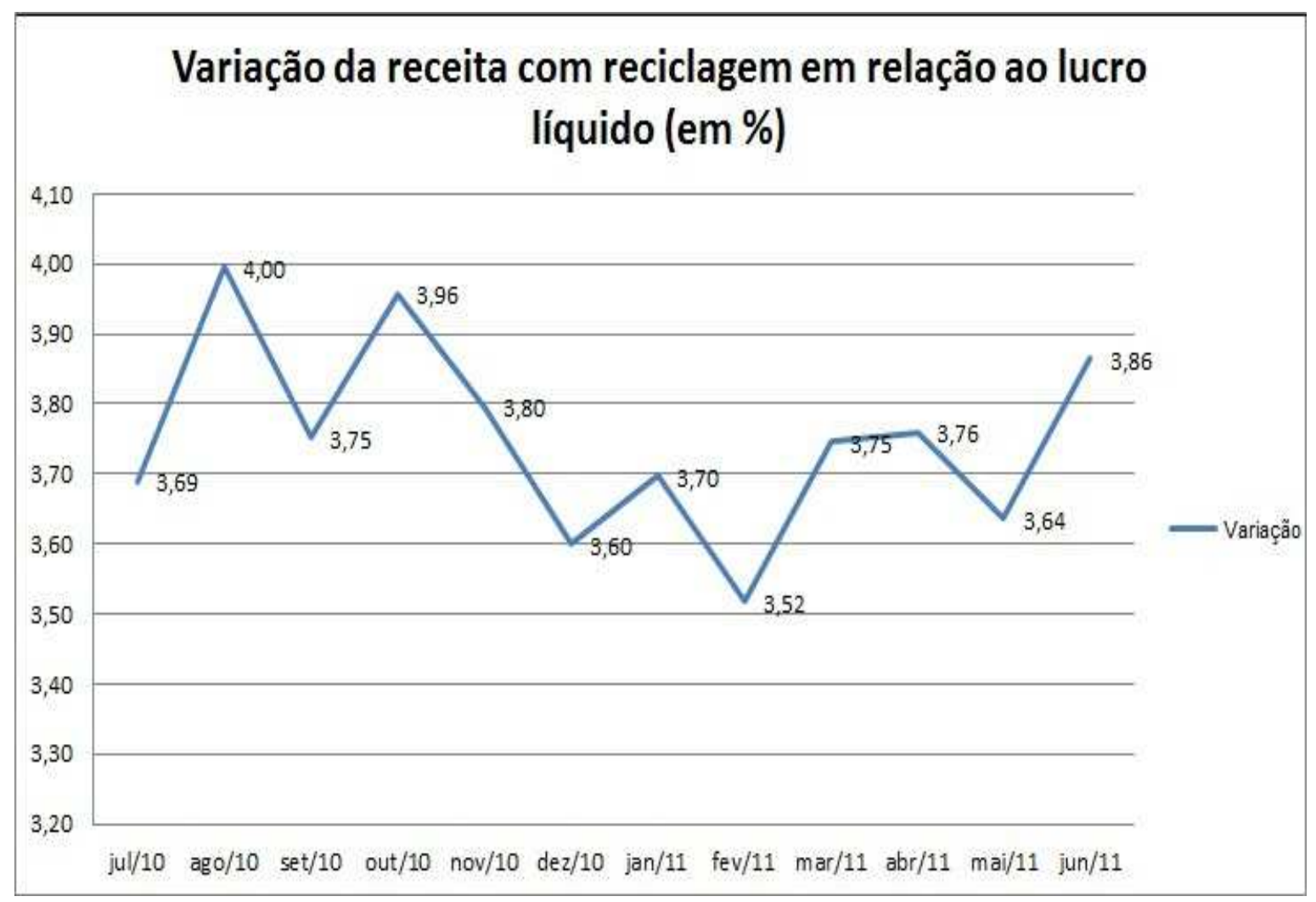

Gráfico 1 - Variação da receita em relação ao lucro líquido.

Fonte: Dados da pesquisa. 
Analisando o gráfico apresentado sobre a variação da receita com a venda dos materiais, pode-se perceber o quanto o supermercado conseguiu recuperar com a venda de materiais recicláveis em relação ao seu faturamento líquido. A variação ficou entre 3,52\% em fevereiro e em 4,00\% em agosto.

O dono do supermercado ratifica que, esse retorno obtido de até $4 \%$ de sua renda liquida faz a diferença, pois esse montante é o suficiente para pagar pelo menos o salário de um funcionário, além de ajudar a preservar o meio ambiente, pois sabemos que essas toneladas de papelão e plásticos provavelmente seriam descartadas de forma incorreta.

O dono do supermercado também cita que: esse trabalho de coleta de materiais recicláveis gera renda, não só para o supermercado, mas também para muitas pessoas da comunidade que, por falta de opção acabam trabalhando com isso, e vivem de coletar materiais pelas ruas do bairro. 
O gráfico, a seguir, apresenta a participação na reciclagem e venda dos materiais que o mercado revende:

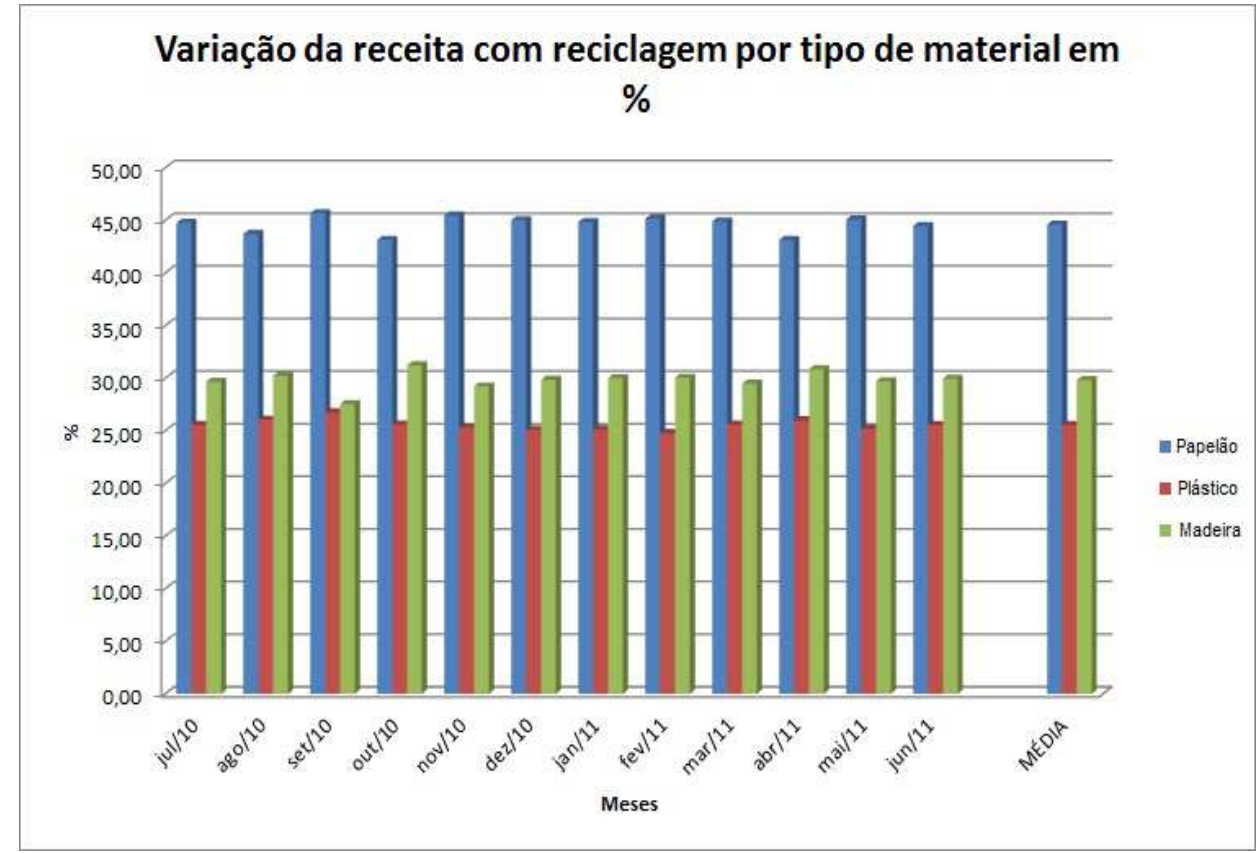

Gráfico 2 - Variação da receita com reciclagem por tipo de material.

Fonte: Dados da pesquisa.

Pode-se perceber que, o material que tem a maior participação em relação à receita total que é obtida com a venda dos materiais do supermercado, é o papelão, com uma média de participação de 44,62 \% no ano, ou seja, do montante vendido entre papelão, caixas de madeira e plásticos, 44,62\% do valor total obtido é referente à venda de papelão.

O segundo material que tem mais participação no valor obtido com as vendas dos materiais são as caixas de madeiras, que geram uma média de $29,82 \%$ da receita. Por último, o plástico tem $25,56 \%$ de participação no valor total recuperado com a venda dos materiais.

No próximo gráfico é possível analisar o quanto o supermercado ganha em reais vendendo cada tipo de material: 


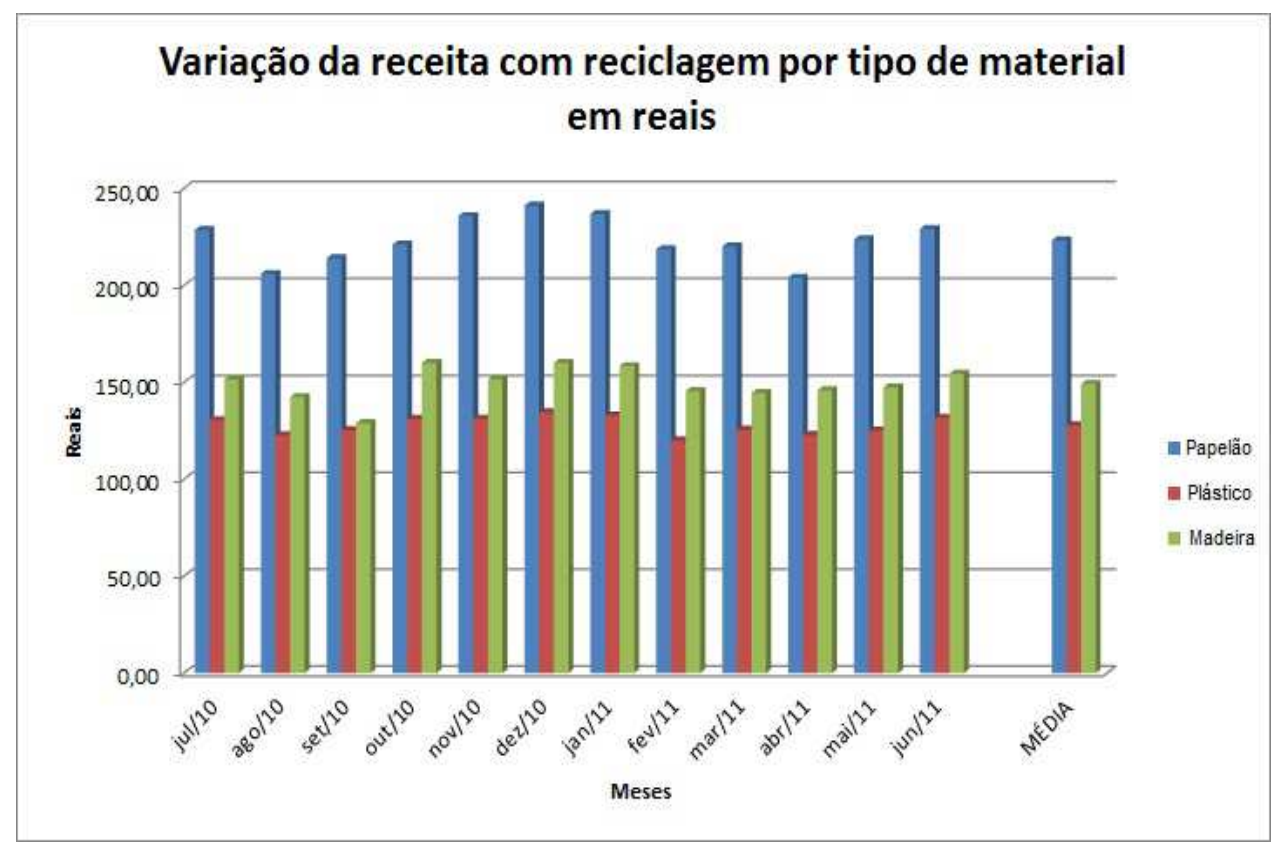

Gráfico 3 - Variação da receita com reciclagem por tipo de material em reais.

Fonte: Dados da Pesquisa

Até por ter maior participação, o papelão é o material que mais gera retorno ao supermercado com sua revenda, alcançando o valor de R \$2.679,94 no ano, ou seja, média de $\mathrm{R} \$ 223,33$ por mês, a venda das caixas de madeira alcançaram o valor anual de $\mathrm{R} \$ 1.791$, ou seja, média de $\mathrm{R} \$ 149,25$ por mês, já a venda do plástico, alcançou o valor de $\mathrm{R} \$ 1.534,08$ por ano, ou seja, média de R $\$ 127,84$ mensais.

Pode-se notar que a quantidade é o principal fator para a rentabilidade do supermercado com os materiais, o plástico é vendido a vinte e cinco centavos por $\mathrm{kg}$, já o papelão é vendido a dez centavos por $\mathrm{kg}$, e mesmo assim é o papelão que compõe a maior parte do valor que o supermercado recupera com a venda de todos os materiais, pois a quantidade de papelão é bem maior do que a quantidade de plástico.

A figura a seguir apresenta o fluxo logístico e o fluxo de logística reversa aplicados ao supermercado:

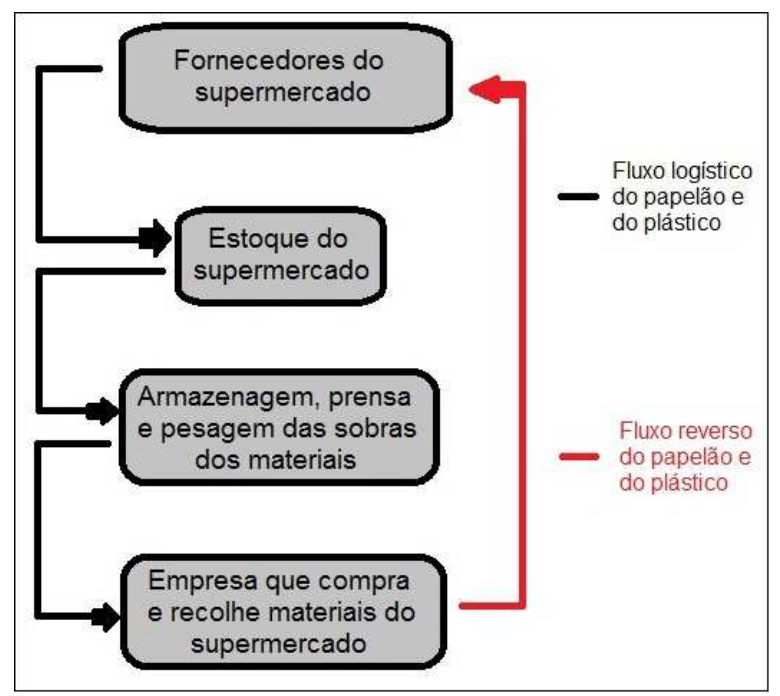

Figura 4 - Fluxos logísticos do supermercado.

Fonte: Dados da Pesquisa 
Analisando a figura é possível perceber todas as etapas da logística do mercado em relação às sobras de papelão e de plástico, bem como da logística reversa aplicada, onde o material depois de ser reciclado pela empresa que compra e recolhe as sobras do supermercado, volta novamente para os fornecedores do supermercado, pois, como dito anteriormente, depois da reciclagem, os produtos passam a ter valor econômico e podem ser reutilizados no ciclo logístico.

Falta ao supermercado maior controle das sobras dos materiais recicláveis, eles são tratados como lixo, porém, como visto anteriormente, esse lixo é o responsável por quase $4 \%$ do faturamento líquido, ou quase responsável pelo pagamento do salário de um funcionário.

Após as pesquisas feitas no supermercado em questão, sugere-se ao gerente que conscientize melhor seus funcionários, para que os mesmos estejam cientes da importância da reciclagem dos materiais, e o que isso significa para o supermercado e também para a comunidade e o meio ambiente. A eficiência da logística reversa em qualquer empresa está condicionada às decisões dos gerentes da mesma, seja qual for o porte e ramo de atividade da empresa. É preciso que o dono ou gerente tome a iniciativa e que passe isso aos seus colaboradores para que o fluxo logístico seja eficaz.

Nota-se, no caso do supermercado que o uso da logística reversa é usado, principalmente, como forma de retorno financeiro para o mesmo e em segundo plano fica a preocupação com a destinação final dos materiais, ou seja, os dois principais benefícios para o supermercado são o retorno financeiro e a despreocupação em ser punido pela severa legislação com o descarte indevido dos materiais.

Uma orientação que pode ser fornecida ao dono do supermercado é que o mesmo aplique em seu estabelecimento a coleta seletiva de materiais, onde as pessoas possam depositar ali materiais como o próprio papelão e plástico, e além desses o dono poderia também usar o espaço para fazer a coleta de pilhas usadas ou vencidas, que acabam sendo prejudiciais ao meio ambiente e até mesmo para as próprias pessoas. Os plásticos e papelões coletados poderiam ser revendidos juntamente com o montante que o supermercado acumulou com as embalagens de seus produtos, podendo assim potencializar os ganhos com a revenda desses materiais coletados, aumentando seu retorno financeiro.

Os funcionários devem estar preparados e orientados para que não desperdicem de forma incorreta materiais que podem ser reaproveitados, é preciso que o dono, a gerência e os funcionários do supermercado tenham a percepção de buscar, sempre que possível, desenvolver a responsabilidade socioambiental de forma cotidiana.

O dono do supermercado, seus funcionários e até seus clientes devem entender que a logística reversa pode se tornar um processo lucrativo para qualquer comércio, como o supermercado em questão, e que, se for bem planejada e executada, a revenda dos materiais recicláveis pode se tornar de um simples fato feito somente para cumprir as leis um fato importante onde além de cumprir as leis, o estabelecimento terá mais lucros e será ecologicamente correto, podendo até se destacar e promover este importante fato para se fortalecer frente a seus concorrentes. 


\section{CONSIDERAÇÕES FINAIS}

O trabalho apresentado mostra como é possível um varejista de pequeno porte usar a logística reversa ao seu favor, bem como os ganhos que ele obtém praticando a logística reversa.

Observou-se que a logística reversa é um diferencial, que pode dar mais competitividade a qualquer tipo de empresa, seja qual for seu ramo de atuação. No exemplo apresentado durante o trabalho, um supermercado de pequeno porte utiliza a logística reversa através da reciclagem de materiais, como plástico e papelão, que antes eram tratados como lixo, para que, ao mesmo tempo em que consiga obter uma determinada receita, também consiga dar um destino ecologicamente correto aos restos de materiais, que com a reciclagem, acabam sendo reaproveitados e acabam voltando ao mercado secundário, para que assim possam ser reutilizados.

Mesmo que esses não sejam os principais objetivos pelos quais o supermercado aplica a logística reversa, a mesma acaba por trazer para o supermercado conceitos e benefícios que, em outras empresas, podem ser de extrema importância, como o da produção limpa, eco eficiência, desenvolvimento sustentável, entre outros. Esses benefícios da logística reversa acabam por gerar valorização para a empresa. No caso do supermercado, notou-se durante as pesquisas que o principal benefício que a logística reversa traz é a possibilidade da criação de uma nova fonte de receita, que, apesar de ser um valor considerado baixo, para um mercado de pequeno porte já representa algo em torno de $3 \%$ a $4 \%$ de seu lucro liquido.

Como apresentado anteriormente, verificou-se que o papelão é o material que mais gera retorno ao supermercado com sua revenda, alcançando o valor de $\mathrm{R} \$ 2.679,94$ no ano, ou seja, média de R \$ 223,33 por mês. A venda das caixas de madeira alcançou o valor anual de R\$ 1.791,00 ou seja, média de R \$ 149,25 por mês. Por sua vez, a venda do plástico, alcançou o valor de $\mathrm{R} \$ 1.534,10$ por ano, ou seja, média de $\mathrm{R} \$ 127,84$ reais mensais.

Notou-se também, durante a pesquisa, que o supermercado precisa ter mais controle no que se refere às sobras de materiais recicláveis, pois, como citado anteriormente, percebe-se que o material é tratado como lixo, sem nenhuma importância, porém, segundo as pesquisas feitas, a venda desse lixo acaba sendo responsável por quase $4 \%$ do faturamento liquido da empresa, ou, o equivalente a um ou mais salários de um funcionário.

Por este motivo o dono do supermercado deve incentivar e orientar seus funcionários sobre a importância do material reciclável, sobre os benefícios adquiridos com o uso da logística reversa e, sobre como os funcionários podem contribuir para que não haja desperdício de materiais, pois com gargalos não é possível obter o máximo de aproveitamento dos materiais.

Como citado anteriormente, ficou claro que o supermercado usa a logística reversa como ferramenta com o objetivo de obter lucro, sua principal preocupação de fato não é com o meio ambiente, porém, ao usar a logística reversa, o mesmo acaba por ajudar na questão ambiental também, além de, obter retorno financeiro. Em outra empresa, de porte e mercado diferentes, o uso da logística reversa pode, além de trazer retorno financeiro, agregar também valor comercial à marca, e isso pode até ser mais importante do que o próprio retorno financeiro, dependendo é claro do ramo e porte da empresa. 
Uma possível forma, apresentada na pesquisa, de potencializar a venda dos materiais recicláveis, se dá com a coleta seletiva de materiais se o supermercado aplicasse a coleta em seu estabelecimento, poderia gerar um acúmulo de materiais, que depois seriam vendidos juntamente com os materiais acumulados no depósito do supermercado, ou seja, seriam vendidos os materiais do supermercado e também os da coleta seletiva, potencializando, assim, o retorno financeiro do supermercado.

O varejo, de forma geral, é um dos principais responsáveis pelo impacto social gerado pelo descarte de materiais e produtos no meio ambiente. Se, de alguma forma, todos se conscientizassem e aderissem a ideia da logística reversa, com certeza o meio ambiente seria menos prejudicado, e, além disso, os próprios varejistas teriam maior margem de lucro, como aconteceu no supermercado estudado.

Conclui-se que, a logística reversa tende a trazer benefícios para a sociedade, seja para os empresários, ou paras as próprias pessoas, que com isso terão maior qualidade de vida, vivendo em um mundo limpo, um mundo ecologicamente correto, onde ferramentas como a logística reversa são fundamentais para diminuir os efeitos dos problemas gerados pelo mundo globalizado.

\section{REFERÊNCIAS}

ACOSTA, Byron; WEGNER, Douglas; PADULA, Antônio Domingos. Logística reversa como mecanismo para redução do impacto ambiental originado pelo lixo informático. RECADM - Revista Eletrônica de Ciência Administrativa / Faculdade Cenecista de Campo Largo. 2008. Paraná - $\quad$ Brasil. Disponível em <http://revistas.facecla.com.br/index.php/recadm/article/view/67/209> acesso em 10/06/2011.

BRAGA JUNIOR, Sergio Silva; COSTA, Priscila Rezende; MERLO, Edgard Monforte. Logística reversa como alternativa de ganho para o varejo: um estudo de caso em um supermercado de médio porte. Anais do IX Simpósio de Administração da produção, logística e operações internacionais. SIMPOI 2006 - FGV - EAESP. 2006. Disponível em <http://www.apoenasustentavel.com.br/arquivos/logistica_reversa.pdf>. Acesso em 20/04/2011

CASTRO, Fransemary da Conceicao; SANTOS, Ivane Mendonca Dos; AGUIAR, Kelly Nascimento De; SILVA, Manoel Rodrigues; RABELO, Sérgio Roberto Costa. Gestão da logística reversa: um estudo de caso da empresa Morepan Alimentos. Centro de ensino Atenas Maranhense, curso de administração. São Luís, 2008. Disponível em <http://pt.scribd.com/doc/8531514/Gestao-da-Logistica-Reversa>. Acesso em 13/07/2011

CHAVES, Gisele de Lorena Diniz; CHICARELLI, Rosane Lucia Alcântara. Logística reversa como atividade geradora de vantagem competitiva ao canal de distribuição de alimentos refrigerados. XII SIMPEP - Bauru, SP, Brasil, 7 a 9 de Novembro de 2005. Disponível em <http://www.feb.unesp.br/dep/simpep/anais/anais_12/copiar.php?arquivo=Chaves_GL_Logisti caReversa.pdf $>$. Acesso em 22/08/2011

LACERDA, Leonardo. Logística empresarial: Armazenagem e localização de instalações. In: FLEURY, P.F.; FIGUEIREDO, K; WANKE, P. (Org.). Logística Empresarial: a perspectiva brasileira. São Paulo: Atlas, 2000.

Logística reversa - Uma visão sobre os conceitos básicos e as práticas operacionais. Centro de Estudos em Logística - COPPEAD - UFRJ. Rio de Janeiro, 2002. 
Disponível em <http://www.paulorodrigues.pro.br/arquivos/Logistica_Reversa_LGC.pdf> acesso em 01/05/2011

LAGO, Elisandro Alves; LÓTICI, Karine Marosin; SILVA, Clairton Tadeu Bidtinger da. Um estudo de caso sobre a implantação de um sistema logístico flexível em uma indústria de embalagens $\quad$ plásticas. $\quad$ Marau $-\mathrm{RS}$. Disponível em $<$ http://www.aedb.br/seget/artigos08/235_Artigo\%20Elisandro\%20Lago\%20com\%20identifica cao.pdf> acesso em 13/04/2011.

LEITE, Paulo Roberto. Logística Reversa: meio ambiente e competitividade. São Paulo: Pearson Prentice Hall, 2003.

NOVAES, Antônio Galvão. Logística e gerenciamento da cadeia de distribuição: estratégia, operação e avaliação. Rio de Janeiro: Campus, 2001.

PIRES, Nara. Modelo para a logística reversa dos bens de pós-consumo em um ambiente de cadeia de suprimentos. Universidade federal de Santa Catarina - UFSC. Florianópolis, 2007. Fornecido pela profa. Patrícia Guarnieri em <http://patriciaguarnieri.blogspot.com>. Acesso em 20/04/2011

ROBLES JR, Antonio; BONELLI, Valério Vitor. Gestão da qualidade e do meio ambiente. Enfoque econômico, financeiro e patrimonial. Editora Atlas. São Paulo. 2006.

ROGERS, Dale S.; TIBBEN-LEMBKE, Ronald S. Going Backwards: Reverse Logistics Trends and Pratices. University of Nevada, 1999. Fornecido pela profa. Patrícia Guarnieri em $<$ http://patriciaguarnieri.blogspot.com>. Acesso em 20/04/2011

ROSA, Elton Tavares. Logística reversa: fator de estratégia empresarial. 2008. Disponível em <http://logisticatotal.com.br/files/articles/606035b6751329f5eef45fb6fcdd9b77.pdf> acesso em 10/06/2011.

TORRE, Guilherme Vitório. Logística verde aplicada à logística reversa: Uma estratégia socioambiental de sucesso. Monografia apresentada à Faculdade de Tecnologia de $\begin{array}{llll}\text { Taquaritinga. } & \text { Taquaritinga. } & \text { Disponível } & \text { em }\end{array}$ <http://pt.scribd.com/doc/40117349/Logistica-Verde-aplicada-a-Logistica-Reversa-umaestrategia-socio-ambiental-de-sucesso\#archive>. Acesso em 19/07/2011. 